\title{
Bioconversion of pretreated wheat straw to ethanol by Monascus purpureus CBS 109.07 and Fusarium venenatum ATCC 20334 using simultaneous saccharification and fermentation
}

\author{
DAVID YUDIANTO ${ }^{1}$, ELLYAS ALGA NAINGGOLAN ${ }^{2}$, RIA MILLATI ${ }^{3, \bullet}$, CHUSNUL HIDAYAT ${ }^{3}$, \\ PATRIK LENNARTSSON ${ }^{4}$, MOHAMMAD J. TAHERZADEH ${ }^{4}$, CLAES NIKLASSON $^{5}$ \\ ${ }^{1}$ Quality Assurance of Food Industry, Politeknik AKA Bogor. Jl. Pangeran Sogiri No. 283, Tanah Baru, Kota Bogor 16154, West Java, Indonesia. \\ Tel./fax.: +62- 251-8650351, email: davidyudianto.se@gmail.com \\ ${ }^{2}$ Department of Bioprocess Engineering, Faculty of Biotechnology, Institut Teknologi Del. Sitoluama, Toba Samosir 22381, North Sumatra, Indonesia \\ ${ }^{3}$ Department of Food and Agricultural Product Technology, Faculty of Agricultural Technology, Universitas Gadjah Mada. Jl. Flora No. 1, Bulaksumur, \\ Sleman 55281, Yogyakarta, Indonesia. Tel./fax.: +62-274-563062, "email: ria_millati@ugm.ac.id \\ ${ }^{4}$ Swedish Center for Resource Recovery, University of Borås. 50190 Borås, Sweden \\ ${ }^{5}$ Department of Chemistry and Chemical Engineering, Chalmers University of Technology. 41296 Gothenburg, Sweden
}

Manuscript received: 27 February 2019. Revision accepted: 21 June 2019

\begin{abstract}
Yudianto D, Nainggolan EA, Millati R, Hidayat C, Lennartsson P, Taherzadeh MJ, Niklasson C. 2019. Bioconversion of pretreated wheat straw to ethanol by Monascus purpureus CBS 109.07 and Fusarium venenatum ATCC 20334 using simultaneous saccharification and fermentation. 20: 2229-2235. Fractions of sulfuric acid-pretreated wheat straw, i.e. solid, liquid, and a mixture of liquid and solid were used as substrates in simultaneous saccharification and fermentation (SSF) process to produce ethanol. The bioconversion was performed by Monascus purpureus CBS 109.07 and Fusarium venenatum ATCC 20334. The highest ethanol yields from solid, liquid and a mixture of solid and liquid fractions by $M$. purpureus CBS 109.07 were $0.36,0.41$, and $0.37 \mathrm{~g} / \mathrm{g}$ glucose, respectively. The corresponding values by $F$. venenatum ATCC 20334 were $0.21,0.54,0.35 \mathrm{~g} / \mathrm{g}$ glucose, respectively.
\end{abstract}

Keywords: Ethanol, Fusarium venenatum ATCC 20334, Monascus purpureus CBS 109.07, Simultaneous Saccharification and Fermentation, wheat straw

\section{INTRODUCTION}

Wheat is one of the major crops in the United Kingdom (UK), and according to a report in 2009 , the annual wheat straw yield was estimated to be between 8 and 10 million tons (Brander et al. 2009). Straws as lignocellulosic materials have been utilized for animal feed or making traditional objects (straw baskets or hats), but a major part of straw is discarded as waste (Hammond and Mansell 2018). One of potential usages of wheat straws is by converting it to more value-added products such as ethanol. The contents of glucan and xylan in wheat straw are approximately $36.3 \%$ and $19 \%$, respectively, and have the potential to be converted to ethanol (Kootstra et al. 2009). Ethanol from lignocellulosic is a renewable fuel, which can reduce $\mathrm{CO}_{2}$ emission and improve fuel combustion.

The basic steps of producing ethanol from lignocellulosic materials are pretreatment, hydrolysis, and fermentation. Cellulase complex can hydrolyze cellulose into monomeric sugars. These monomeric sugars can be converted to ethanol by simultaneous saccharification and fermentation (SSF) method, for example by $M$. purpureus CBS 109.07 and $F$. venenatum ATCC 20334. The previous study by Takeshita et al. (2016) showed that combination of Monascus purpureus NBRC 5965 and Saccharomyces cerevisiae $\mathrm{K} 7$ could produce ethanol in alcoholic beverages. The results showed that $M$. purpureus has the capability as saccharification agent and ethanol producer. Monascus purpureus is not only used as a food colorant, flavoring agent, and preservative, but it is also widely applied in medical purposes to lower blood cholesterol, anti-diabetes, anti-inflammatory and to prevent osteoporosis (Arunachalam and Narmadhapriya 2011). F. venenatum has been cultured as a mycoprotein for a food source. Food products from $F$. venenatum have a fibrous texture and become rich source of high-quality protein, including essential amino acids (Hosseini and KhosraviDarani 2010). M. purpureus CBS 109.07 and $F$. venenatum ATCC 20334 are still considered as new strains especially for ethanol production from lignocellulose.

The wheat straw used in this study had been pretreated using acid method to render the crystalline structure of the cellulose. The solid fraction of pretreated wheat straw contains high cellulose that can be used by fungi to produce ethanol in SSF, while the liquid fraction contains monomeric sugars. A mixture of solid and liquid fractions can be used as substrate for ethanol production in SSF. In SSF, glucose released during biomass saccharification strongly inhibits enzymes, particularly $\beta$-D-glucosidase that catalyzes hydrolysis of cellobiose to glucose. In SSF, glucose would be continuously converted to ethanol through a fungal fermentation process so that inhibition of enzymes by glucose can be avoided. To the best of our knowledge, there have been no studies on ethanol 
production by $M$. purpureus CBS 109.07 and $F$. venenatum ATCC 20334 from wheat straw. Therefore, M. purpureus (CBS 109.07) together with $F$. venenatum ATCC 20334 were used to produce ethanol from wheat straw in this study. Therefore, the objective of this study was to evaluate ethanol production by $M$. purpureus CBS 109.07 and $F$. venenatum ATCC 20334 from a solid, liquid, mixed fraction (solid and liquid fractions) of pretreated wheat straw by SSF method.

\section{MATERIALS AND METHODS}

\section{The Microorganisms}

Monascus purpureus CBS 109.07 and F. venenatum ATCC 20334 used in this study were obtained from Swedish Center for Resource Recovery, University of Borås, Sweden. These fungi were maintained on Potato Dextrose Agar (PDA) at $4{ }^{\circ} \mathrm{C}$. The spore suspension was prepared by adding $20 \mathrm{ml}$ of $0.05 \mathrm{M}$ citrate buffer into agar plate. The spore suspension was dispersed with a disposable spreader.

\section{The Pretreated wheat straw}

Pretreated wheat straw used in this study was obtained from the Swedish Center for Resource Recovery, University of Borås, Sweden. The chemical composition of the pretreated wheat straw is presented in Table 1. The wheat straw had been pretreated at SEKAB in Örnsköldsvik, Sweden. Pretreatment was conducted at 20 bar and $\mathrm{pH} 1.7$ (adjusted with $\mathrm{H}_{2} \mathrm{SO}_{4}$ ) for 5-7 min. The pretreated wheat straw was stored at $4^{\circ} \mathrm{C}$ for further use.

Before fermentation process, the pretreated wheat straw was neutralized (detoxified) by sodium hydroxide $10 \mathrm{M}$ because fungi could not grow on the pretreated wheat straw at very low $\mathrm{pH}$ condition. The pretreated wheat straw was diluted with deionized water $(1: 1)$ and added with $10 \mathrm{M}$ sodium hydroxide until it reached $\mathrm{pH}$ 5.5. Filtration was carried out by filtering the pretreated wheat straw on the crucibles to separate the solid and the liquid fraction. The solid, the liquid, and the mixed fraction (a mixture of solid and liquid fractions) of pretreated wheat straw after detoxification process were individually used as substrates for $M$. purpureus CBS 109.07 and $F$. venenatum ATCC 20334 in the SSF process to produce ethanol. SSF of Avicel was also performed as reference (positive control).

Table 1. Chemical composition of pretreated wheat straw

\begin{tabular}{lc}
\hline Analysis & Concentration (\% dry weight) \\
\hline Total solid & 19.74 \\
Cellulose & 41.13 \\
Acid-insoluble lignin & 29.10 \\
Acid soluble lignin & 0.71 \\
Total lignin & 29.82 \\
Ash & 6.45 \\
\hline
\end{tabular}

\section{Enzymes activity}

Two commercial enzymes, i.e. cellulase complex (NS22086) from Novozymes (Denmark) and $\beta$-glucosidase from almonds (Sigma-Aldrich, Germany) were used in all experiments as enzymatic complex. The activity of cellulase complex (NS22086) was 325 FPU/mL according to the method described by Yu et al. (2015). The activity of $\beta$-glucosidase was 2 units/mg solids.

\section{Cultivation of microorganisms}

The media for culturing microorganisms contained (g/L): glucose 50; yeast extract 5; $\left(\mathrm{NH}_{4}\right)_{2} \mathrm{SO}_{4} 7.5 ; \mathrm{K}_{2} \mathrm{HPO}_{4}$ $3.5 ; \mathrm{MgSO}_{4} .7 \mathrm{H}_{2} \mathrm{O} 0.75 ; \mathrm{CaCl}_{2} .2 \mathrm{H}_{2} \mathrm{O} 1$ and $0.05 \mathrm{M}$ citrate buffer at $\mathrm{pH} 5.5$. Fifty $\mathrm{mL}$ of medium in $250 \mathrm{~mL}$ cottonplugged Erlenmeyer flasks were autoclaved at $121^{\circ} \mathrm{C}$. After reaching room temperature; the medium was inoculated with the fungal microorganism. One milliliter of spore suspension, containing $1 \times 10^{6}$ spores $/ \mathrm{mL}$ of $M$. purpureus CBS 109.07 or $F$. venenatum ATCC 20334, was added to each flask. The fungal culture was incubated for 30 hours at $30^{\circ} \mathrm{C}$ at $150 \mathrm{rpm}$. At the end of incubation, the content of Erlenmeyer flasks was aseptically centrifuged and was further used in SSF.

\section{Fermentation of pretreated wheat straw}

SSF was performed under anaerobic conditions. The media contained $(\mathrm{g} / \mathrm{L})$ : yeast extract 5; $\left(\mathrm{NH}_{4}\right)_{2} \mathrm{SO}_{4} \quad 7.5$; $\mathrm{K}_{2} \mathrm{HPO}_{4} 3.5 ; \mathrm{MgSO}_{4} .7 \mathrm{H}_{2} \mathrm{O} 0.75 ; \mathrm{CaCl}_{2} .2 \mathrm{H}_{2} \mathrm{O}$ 1; either solid fraction of pretreated wheat straw 250 or a mixture of solid and liquid fraction of pretreated wheat straw 250 or pure cellulose (Avicel) 50; and $0.05 \mathrm{M}$ buffer citrate. Meanwhile, the liquid fraction of pretreated wheat straw had a concentration of $100 \mathrm{~mL} / \mathrm{L}$ media. The final volume in each flask was $100 \mathrm{~mL}$. The $\mathrm{pH}$ of the media was adjusted to 5.5 with the addition of $10 \mathrm{M} \mathrm{NaOH}$. All the media were autoclaved at $121^{\circ} \mathrm{C}$ for $15 \mathrm{~min}$. The media were then inoculated with $1 \mathrm{~g}$ of the fungus (dry base). The required enzymes were also added into each flask aseptically. All the SSF experiments were performed at $30^{\circ} \mathrm{C}$. The enzyme loading was $15 \mathrm{FPU} / \mathrm{g}$ cellulose and 30 IU/g total solid of pretreated wheat straw. The flasks were equipped with a loop-trap containing water and sterile plastic tubes as well as clamps for taking liquid samples Christia et al. (2016).

\section{Analysis of pretreated wheat straw}

The pretreated wheat straw was analyzed for the ash content (Isroi et al. 2012), total solids (Isroi et al. 2012), total lignin (Sluiter et al. 2012) and cellulose content (Sluiter et al. 2012). The samples from SSF were analyzed by a High-Performance Liquid Chromatography (HPLC) (Isroi et al. 2012), which was equipped with UV/vis and RI detectors (Waters, UK). Cellobiose, glucose, xylose, and mannose were analyzed in the Biorad Aminex HPX-87P column (Bio-Rad, Richmond, CA, USA) equipped with the appropriate guard column with the HPLC conditions as follows: $25 \mu \mathrm{L}$ injection volume, $0.2 \mu \mathrm{m}$ filtered and degassed HPLC grade water mobile phase, $0.6 \mathrm{~mL} /$ minute flow rate, $85^{\circ} \mathrm{C}$ column temperature, 35 minutes run time. The analysis of ethanol, xylitol, glycerol, furfural, lactic, 
acetic, and succinic acids were conducted according to the National Renewable Energy Laboratory (NREL) procedure that has been modified by Isroi et al. (2012). Those compounds were analyzed in the Biorad Aminex HPX-87H column (Bio-Rad, Richmond, CA, USA) equipped with the appropriate guard column with the HPLC conditions as follows: $25 \mu \mathrm{L}$ injection volume, $0.2 \mu \mathrm{m}$ filtered and degassed $0.005 \mathrm{M}$ sulfuric acid mobile phase, 0.6 $\mathrm{mL} / \mathrm{minute}$ flow rate, $60^{\circ} \mathrm{C}$ column temperature, 50 minutes run time.

\section{RESULTS AND DISCUSSION}

\section{Composition of pretreated wheat straw}

It can be seen in Table 1 that the percentages of total solids and cellulose were $19.74 \%$ and $41.13 \%$, respectively. The percentage of cellulose was considerably high. Cellulose in wheat straw comprises of cellulose I allomorph with low crystallinity, and the stable cellulose $I_{\beta}$ with polymorphic crystal structure (Volynets and Dahman 2011). Cellulose microfibrils are connected by amorphous serrated area in longitudinal formation in the epidermis, while in the parenchyma, they have a random arrangement. Cellulose microfibrils are entrapped in hemicellulose by hydrogen and covalent bond, which are stuck together by lignin. Yang et al. (2018) stated that the cellulose content in parenchyma is higher than in the epidermis. This phenomenon also occurs in every part in tissues, especially in vascular bundles and parenchyma tissue during plant growth. Furthermore, there is a similar crystallinity character of wheat straw's cellulose in different parts (Zhang et al. 2014). In epidermis, the cellulose is orientated along the growth direction, whereas in the parenchyma, there is no preferred orientation along the growth direction.

Total lignin of the pretreated wheat straw was $29.82 \%$, which contains the acid-insoluble lignin $(29.1 \%)$ and the soluble acid lignin (0.71\%). A study by Qi et al. (2010) showed that the acid-insoluble lignin in pretreated wheat straw ranging from about $16 \%$ (pretreated with $0 \%$ sulfuric acid) to $33 \%$ (pretreated with $3 \%$ sulfuric acid). More severe pretreatment conditions resulted in higher acidinsoluble lignin in the pretreated solids (Qi et al. 2010). Total lignin in this study was quite high $(29.82 \%$ of dry weight). This result indicates that there was no destruction of the lignin structure during pretreatment process. It means that only lignin bound to hemicelluloses that were damaged so that the lignin content in the substrate remains high. However, there is a possibility that chemical bonds between hemicellulose and cellulose may inhibit the cellulolytic enzyme activity. The presence of lignin and hemicellulose inhibits cellulolytic enzyme activity because of the structure of hemicellulose, which traps cellulose. The cellulolytic enzyme will have difficulty in hydrolyzing cellulose directly.

The ash content in the pretreated wheat straw was $6.45 \%$. This value was slightly different from the ash content of raw wheat straw (7.9\%) (Bakisgan et al. 2009). The differences in ash content might be caused by the acid pretreatment process carried out to wheat straw in this study. Inorganic materials have association with lignocellulosic components especially hemicellulose in some biomass ashes (Vassilev et al., 2014). Acid pretreatment leads to degradation of lignocellulosic components, i.e. lignin and hemicellulose to its monomers. Whereas, untreated wheat straw still has a lot of lignocellulosic components associated with inorganic materials, which could be taken into account as ash during analysis.

\section{Simultaneous saccharification and fermentation by $M$. purpureus CBS 109.07}

SSF of pretreated wheat straws (solid, liquid, and mixed solid and liquid fraction) were carried out under anaerobic condition. SSF with Avicel was also conducted as a reference/positive control. Cellulase and $\beta$-glucosidase enzymes produced glucose from the cellulose part of the pretreated wheat straws and M. purpureus CBS 109.07 simultaneously assimilated the glucose to ethanol. These enzymes help to increase the amount of ethanol yield during fermentation. M. purpureus CBS 109.07 is a cellobiose-utilizing microorganism, which can facilitate saccharification of cellulose. Fermentation of M. purpureus CBS 109.07 in the liquid fraction of pretreated wheat straw resulted in the highest maximum ethanol yield in SSF $(0.41$ $\mathrm{g} / \mathrm{g}$ glucose) (Table 2), while the highest rate of ethanol production was obtained on the $2^{\text {nd }}$ to the $3^{\text {rd }}$ day of the fermentation process (Figure 1a). The ethanol concentration remained constant on the last 4 days of fermentation of the solid fraction, but it decreased slowly in the liquid fraction as well as in mixed (solid and liquid) fraction. Ethanol concentration increased in Avicel media. The increased ethanol production by $M$. purpureus CBS 109.07 in solid, liquid, and mixed fraction of pretreated wheat straw in SSF occurred on day-1 to day-3 of the fermentation process. The maximum ethanol concentration in Avicel medium was obtained on day-7 (Figure 1.A).

The concentration profiles of glucose, cellobiose, xylose, and mannose are presented in Figure 1.B-E. All of the simple sugars are intermediate products in the bioconversion chains from lignocellulosic biomass to ethanol. The concentrations of cellobiose, xylose, and mannose throughout all the experiments except glucose were less than $0.2,0.8$, and $0.51 \mathrm{~g} / \mathrm{L}$, respectively. The maximum glucose concentrations in a solid, liquid, a mixture of solid and liquid fractions of pretreated wheat straw, and Avicel were 17.94, 4.69, 8.81, $36.19 \mathrm{~g} / \mathrm{L}$, respectively. Each medium had different total solid content, except the liquid fraction of pretreated wheat straw. The total solid contents of the solid, a mixture of solid and liquid fractions of pretreated wheat straw, and Avicel were 4.93, 2.46, and $5 \mathrm{~g}$, respectively. The cellulose contents of solid, a mixture of solid and liquid, and Avicel were 2, 1, and 5, respectively. The cellulose contents were calculated based on cellulose content of pretreated wheat straw (41.13\% dry weight). Therefore, the maximum glucose concentrations in a solid, liquid, a mixture of solid and liquid fractions of pretreated wheat straw, and Avicel were different. 
Furthermore, Kootstra et al (2009) stated that xylan was the dominant sugar in hemicelluloses of wheat straw $(19 \%)$. Therefore, if the microorganisms can utilize both hexose and xylose that are present in the hydrolyzate, higher ethanol yield can be expected. There are several microorganisms that can produce ethanol from xylose. The results of the study by Qi et al. (2010) showed that the liquid fraction of pretreated wheat straw using $2 \%$ and $3 \%$ acid concentration yield the highest glucose content. Furthermore, study by Qi et al. (2010) also showed that xylose was the main monomeric sugar in all of the liquid fraction of pretreated wheat straw, and its yield was also significantly affected by acid concentration. Increasing acid concentration led to increased xylose yield. According to Qi et al. (2010), the highest xylose yield was $0.23 \mathrm{~g}$ xylose/g wheat straw when the straw was pretreated with $2 \%$ sulfuric acid. Acid concentration $>2 \%$ caused a slight decrease in xylose yield. Higher acid concentration causes further degradation of xylose to furfural.

Acetic acid was the major byproduct of SSF by $M$. purpureus CBS 109.07. The highest concentration of acetic acid was obtained from a liquid fraction of pretreated wheat straw $(0.23 \mathrm{~g} / \mathrm{g}$ biomass $)$. The time courses of acetic acid production were similar to the time courses of ethanol. No further accumulation of acetic acid was obtained after 4 days of SSF. The yields of the other metabolites (xylitol, glycerol, furfural, succinic, and lactic acids) were negligible in all the SSF experiments by $M$. purpureus CBS 109.07, which were in the range of $0-0.08 \mathrm{~g} / \mathrm{g}$ biomass (Table 2).
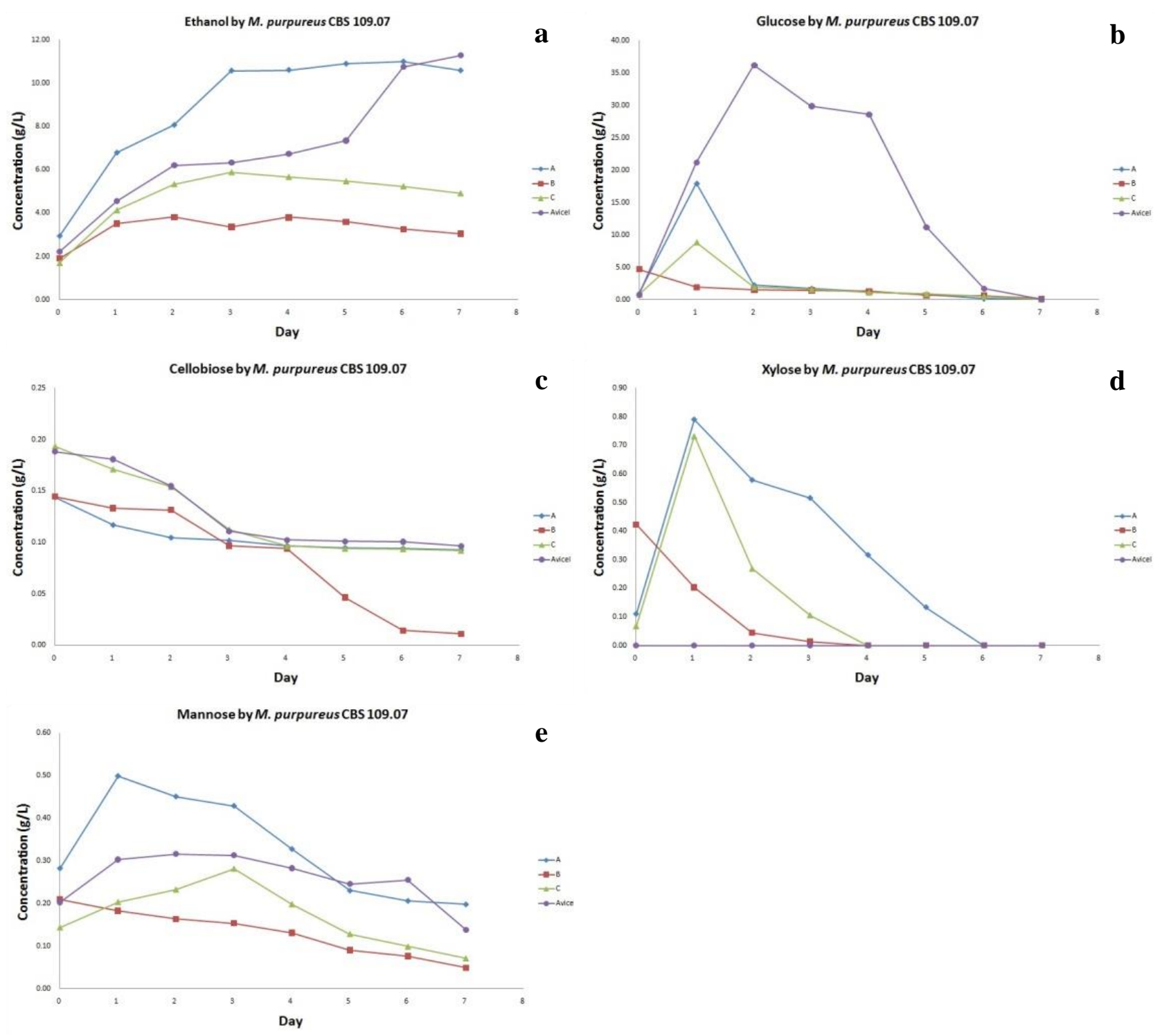

Figure 1. Concentration Profile of: (a). Ethanol, (b). Glucose, (c). Cellobiose, (d). Xylose, and (e). Mannose during SSF of Pretreated Wheat Straw and Avicel by M. purpureus CBS 109.07. (A) = solid fraction of pretreated wheat straw, (B) $=$ liquid fraction of pretreated wheat straw, $(\mathrm{C})=$ a mixture of the solid and liquid fraction of pretreated wheat straw 

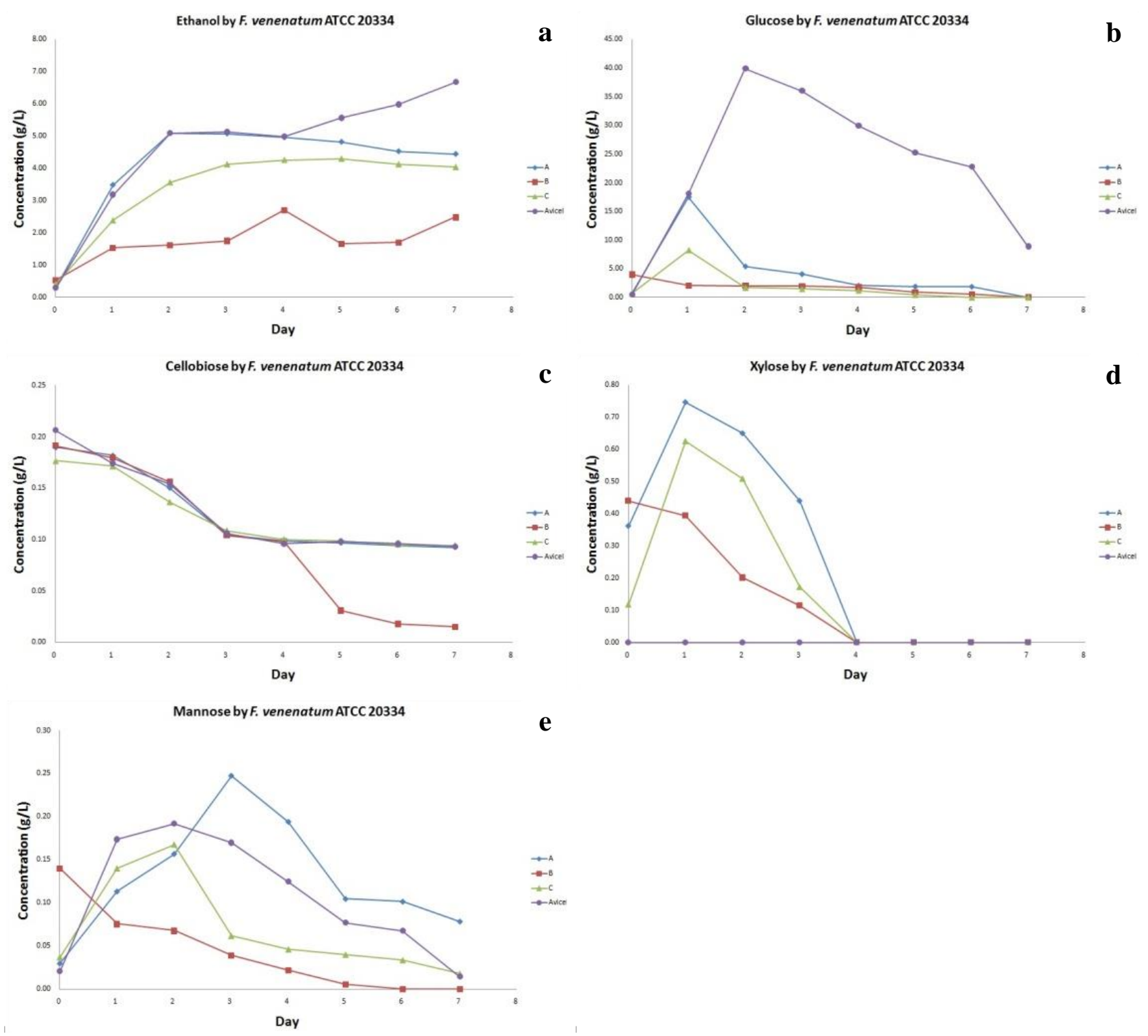

Figure 2. Concentration Profile of (a). Ethanol, (b). Glucose, (c). Cellobiose, (d). Xylose, and (e). Mannose during SSF of Pretreated Wheat Straw and Avicel by F. venenatum ATCC 20334. (A) = solid fraction of pretreated wheat straw, (B) $=$ liquid fraction of pretreated wheat straw, $(C)=$ a mixture of the solid and liquid fraction of pretreated wheat straw

\section{Simultaneous Saccharification and Fermentation by $F$.} venenatum ATCC 20334

Ethanol production from pretreated wheat straw in SSF was also conducted using $F$. venenatum ATCC 20334. SSF of Avicel was also carried out as a control. The results are presented in Figure 2 and Table 2. F. venenatum ATCC 20334 is a filamentous fungus quite similar to $M$. purpureus CBS 109.07 in terms of formation of the metabolites, in which ethanol was the main metabolite and the main byproduct was acetic acid. The profile of ethanol formation (Figure 2.a) was quite similar to the $M$. purpureus CBS 109.07, where the major part of ethanol was produced in the first 2 to 3 days of fermentation. The concentration of ethanol remained constant within the last 4 days of SSF of the liquid fraction and a mixture of the solid and liquid fraction of pretreated wheat straw. However, it decreased slowly in the solid fraction of pretreated wheat straw and increased in Avicel. The results showed that ethanol production by $F$. venenatum ATCC 20334 in all the substrates occurred on day-1 to day-4. However, it took about 7 days or more to reach the maximum ethanol concentration in Avicel (Figure 2a). The best ethanol yield by $F$. venenatum ATCC 20334 was $0.54 \mathrm{~g} / \mathrm{g}$ glucose, which was obtained from the liquid fraction of pretreated wheat straw in SSF (Table 2). Enzymes act to enhance the overall ethanol yield from cellulose. Sakamoto et al. (2012) showed that addition of hemicellulolytic enzymes increased the production of monomeric sugars and ethanol from hemicellulosic materials of rice straw. The ethanol was produced not only from glucose but also from other monomeric sugars, such as cellobiose, xylose, and mannose. Therefore, if all those monomeric sugars could be assimilated, the theoretical ethanol yield could be higher than that of Table 2 . 
Table 2. Yield of ethanol and byproducts and ethanol concentration in simultaneous saccharification and fermentation of dilute-acid pretreated wheat straw with M. purpureus CBS 109.07 and F. venenatum ATCC 20334.

\begin{tabular}{|c|c|c|c|c|c|c|c|c|c|c|c|c|}
\hline \multirow[b]{2}{*}{ Strain } & \multirow[b]{2}{*}{ Substrate } & \multirow[b]{2}{*}{$\begin{array}{c}\text { Total } \\
\text { solid }(\mathrm{g} / \mathrm{L})\end{array}$} & \multirow{2}{*}{$\begin{array}{l}\text { Cellulose } \\
\text { content } \\
(\mathrm{g} / \mathrm{L})\end{array}$} & \multirow{2}{*}{$\begin{array}{c}\text { Max } \\
\text { ethanol } \\
\text { concentrati } \\
\text { on }(\mathrm{g} / \mathrm{L}) \\
\end{array}$} & \multirow{2}{*}{$\begin{array}{c}\text { Max } \\
\text { theoretical } \\
\text { ethanol yield } \\
(\%)\end{array}$} & \multicolumn{4}{|c|}{ Max Yield (g/g glucose) } & \multirow[b]{2}{*}{ Glycerol } & \multirow[b]{2}{*}{$\begin{array}{l}\text { Acetic } \\
\text { acid }\end{array}$} & \multirow[b]{2}{*}{ Furfural } \\
\hline & & & & & & Ethanol & Xylitol & $\begin{array}{c}\text { Succinic } \\
\text { acid }\end{array}$ & $\begin{array}{c}\text { Lactic } \\
\text { acid }\end{array}$ & & & \\
\hline M. purpureus & A & 49.35 & 20.30 & 8.08 & $70.26^{\mathrm{a}}$ & 0.36 & 0.00 & 0.01 & 0.08 & 0.01 & 0.16 & 0.00 \\
\hline \multirow[t]{3}{*}{ CBS 109.07} & B & - & $4.69 *$ & 1.92 & $80.06^{\mathrm{b}}$ & 0.41 & 0.00 & 0.06 & 0.00 & 0.02 & 0.23 & 0.00 \\
\hline & $\mathrm{C}$ & 24.68 & 10.15 & 4.19 & $72.86^{\mathrm{a}}$ & 0.37 & 0.00 & 0.01 & 0.02 & 0.01 & 0.11 & 0.00 \\
\hline & Avicel & 50.00 & 50.00 & 9.07 & $32.11^{\mathrm{a}}$ & 0.16 & 0.00 & 0.00 & 0.04 & 0.00 & 0.01 & 0.00 \\
\hline F. venenatum & A & 49.35 & 20.30 & 4.79 & $41.65^{\mathrm{a}}$ & 0.21 & 0.00 & 0.00 & 0.11 & 0.01 & 0.02 & 0.01 \\
\hline \multirow[t]{3}{*}{ ATCC 20334} & $\mathrm{~B}$ & - & $3.98^{*}$ & 2.16 & $78.62^{b}$ & 0.54 & 0.02 & 0.05 & 0.05 & 0.02 & 0.32 & 0.01 \\
\hline & $\mathrm{C}$ & 24.68 & 10.15 & 3.89 & $67.65^{\mathrm{a}}$ & 0.35 & 0.01 & 0.01 & 0.03 & 0.01 & 0.11 & 0.01 \\
\hline & Avicel & 50.00 & 50.00 & 6.38 & $22.59^{\mathrm{a}}$ & 0.12 & 0.00 & 0.00 & 0.04 & 0.00 & 0.04 & 0.00 \\
\hline
\end{tabular}

Note: * Glucose content in Liquid Fraction of Pretreated Wheat Straw. ${ }^{a}$ Max theoretical ethanol yield (solid, both of solid and liquid fraction, Avicel $)=[[$ max produced ethanol $(\mathrm{g} / \mathrm{L})] /[0.51 \times 1.111 \times$ dry weight of biomass $(\mathrm{g} / \mathrm{L}) \times \mathrm{F}]] \times 100 . \mathrm{F}=$ cellulose fraction in biomass

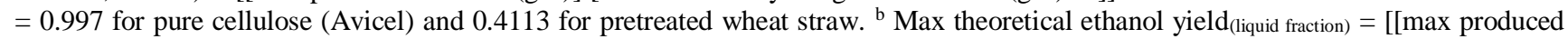
ethanol $(\mathrm{g} / \mathrm{L})] /[$ initial glucose concentration in liquid fraction of pretreated wheat straw $(\mathrm{g} / \mathrm{L})]] \times 100 .{ }^{\mathrm{c}}$ Max yield $=[(\max$ produced $(\mathrm{g} / \mathrm{L})$-initial production $(\mathrm{g} / \mathrm{L})] /[1.111 \times$ dry weight of biomass $(\mathrm{g} / \mathrm{L}) \times \mathrm{F}]$, where $\mathrm{F}=$ cellulose fraction in biomass $=0.997$ for pure cellulose (Avicel) and 0.4113 for pretreated wheat straw. $\mathrm{A}=$ solid fraction of pretreated wheat straw. $\mathrm{B}=$ liquid fraction of pretreated wheat straw. $\mathrm{C}=\mathrm{a}$ mixture of the solid and liquid fraction of pretreated wheat straw

In this study, ethanol yield in SSF of Avicel was lower than that of solid, liquid, and a mixture of solid and liquid fractions of pretreated wheat straw in all of the experiments (Table 2). This is similar to the results of the previous works, in which glucose and ethanol yields of pretreated sugar cane bagasse by cellulignin were higher than that of pure cellulose Avicel (Ferreira et al. 2010). Some other factors may also affect the ethanol yield. Physical properties and cellulose microstructure are among the potential factors that affect enzymatic hydrolysis (Ogeda et al. 2012). Furthermore, Avicel was purchased in dried form. It was reported that drying might damage the pores of the biomass irreversibly (Amit et al. 2018). Another reason of the lower yield in SSF of Avicel might be caused by the higher ethanol concentration in SSF of Avicel, which could reduce the activity of the enzyme (Márkus et al. 2017) and viability of microorganism (Chauhan et al. 2013).

The presence of residues of hemicellulose and lignin in the pretreated wheat straw could reduce the performance of the fungi during the bioconversion process of sugars to ethanol. It makes the ethanol yield in liquid fraction of pretreated wheat straw higher than that of in solid fraction and in a mixture of solid and liquid fraction of pretreated wheat straw.

The concentration profiles of glucose, cellobiose,

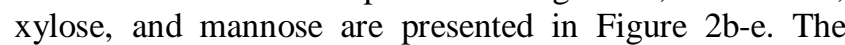
concentrations of cellobiose, xylose, and mannose in SSF by F.venetatum remained under $0.22,0.76$, and $0.26 \mathrm{~g} / \mathrm{L}$, respectively throughout all the experiments except glucose. The maximum glucose concentrations resulted from a solid, liquid, mixture of solid and liquid fractions of pretreated wheat straw, and Avicel were 17.49, 3.98, 8.23, $39.93 \mathrm{~g} / \mathrm{L}$, respectively. The total solids and cellulose content of the solid, a mixture of solid and liquid fractions of pretreated wheat straw, and Avicel were similar to SSF by $M$. purpureus. F.venetatum also produced acetic acid as the main byproduct and the highest yield of acetic acid was obtained from the fermentation of liquid fraction of pretreated wheat straw $(0.32 \mathrm{~g} / \mathrm{g}$ biomass $)$, while the yields of acetic acid in solid, a mixture of solid and liquid fraction of pretreated wheat straw, and Avicel were 0.02 and 0.14 $\mathrm{g} / \mathrm{g}$ biomass (Table 2). The yields of the other metabolites were negligible in all SSF experiments by $F$. venenatum ATCC 20334. The maximum yield of xylitol was in the range of $0-0.02$, succinic acid was $0-0.05$, lactic acid was $0.03-0.11$, glycerol was $0-0.02$, and furfural was $0-0.01 \mathrm{~g} / \mathrm{g}$ biomass (Table 2).

Based on the results of this study, it can be concluded that $M$. purpureus CBS 109.07 and $F$. venenatum ATCC 20334 were able to produce ethanol from liquid and solid fraction of pretreated wheat straw. M. purpureus CBS 109.07 produced higher ethanol in the liquid and the solid fraction of pretreated wheat straw than $F$. venenatum ATCC 20334 did.

\section{ACKNOWLEDGEMENTS}

This work was financially supported by The Swedish Council for Higher Education through Linnaeus-Palme Program.

\section{REFERENCES}

Amit K, Nakachew M, Yilkal B, Mukesh Y. 2018. A review of factors affecting enzymatic hydrolysis of pretreated lignocellulosic biomass. Res J Chem Environ 22 (7): 62-67 
Arunachalam C, Narmadhapriya D. 2011. Monascus fermented rice and its beneficial aspects: a new review. Asian J Pharm Clin Res 4 (1): 29-31.

Bakisgan C, Dumanli AG, Yürüm Y. 2009. Trace elements in Turkish biomass fuels: Ashes of wheat straw, olive bagasse and hazelnut shell. Fuel 88: 1842-1851.

Brander M, Hutchison C, Sherrington C, Ballinger A, Beswick C, Baddeley A, et al. 2009. Methodology and evidence base on the indirect greenhouse gas effects of using wastes, residues, and byproducts for biofuels and bioenergy-appendix 10 wheat straw case study-Data and Assumptions, In: Davis G, (editor). Report to RFA and DECC. Ecometrica.

Chauhan NM, Shinde RB, Karuppayil SM. 2013. Effect of alcohols on filamentation, growth, viability and biofilm development in Candida albicans. Braz J Microbiol 44 (4): 1315-1320.

Christia A, Setiowati AD, Millati R, Karimi K, Cahyanto MN, Niklasson C, Taherzadeh MJ. 2016. Ethanol production from alkali- pretreated oil palm empty fruit bunch by simultaneous saccharification and fermentation with Mucor indicus. Intl J Green Energ 13 (6): 566-572.

Ferreira V, Faber MO, Mesquita SS, Pereira N. 2010. Simultaneous saccharification and fermentation process of different cellulosic substrates using a recombinant Saccharomyces cerevisiae harboring the $\beta$-glucosidase gene. Electron J Biotechn 13 (2): 1-7.

Hammond GP, Mansell RM. 2018. A comparative thermodynamic evaluation of bioethanol processing from wheat straw. Appl Energ 224: 136-146.

Hosseini S, Khosravi-Darani K. 2010. Response surface methodology for mycoprotein production by $F$. venenatum ATCC 20334. J Bioprocess Biotechniq 1: 102. DOI: 10.4172/2155-9821.1000102

Isroi, Ishola MM, Millati R, Syamsiah S, Cahyanto MN, Niklasson C, Taherzadeh MJ. 2012. Structural changes of oil palm empty fruit bunch (OPEFB) after fungal and phosphoric acid pretreatment. Molecules 17: 14995-15012.

Kootstra AM J, Beeftink H H, Scott EL, Sanders JPM. 2009. Comparison of dilute mineral and organic acid pretreatment for enzymatic hydrolysis of wheat straw. Biochem Eng J 46 (2): 126-131.

Kootstra AMJ, Beeftink HH, Scott EL, Sanders JPM. 2009. Optimization of the dilute maleic acid pretreatment of wheat straw. Biotechnol Biofuels 2: 31 DOI: 10.1186/1754-6834-2-31.
Márkus Z, Bakó KB, Tóth G, Nemestóthy N, Gubicza L. 2017. Effect of chain length and order of alcohol on enzyme activity during enzymatic esterification in organic media. Hung J Ind Chem 45 (2): 35-39.

Ogeda TL, Silva IB, Fidale LC, Seoud OAE, Petri DFS. 2012. Effect of cellulose physical characteristics, especially the water sorption value, on the efficiency of its hydrolysis catalyzed by free or immobilized cellulose. J Biotechnol 157: 246- 252.

Qi B, Chen X, Wan Y. 2010. Pretreatment of wheat straw by nonionic surfactant-assisted dilute acid for enhancing enzymatic hydrolysis and ethanol production. Bioresour Technol 101 (13): 4875-4883.

Sakamoto T, Hasunuma T, Hori Y, Yamada R, Kondo A. 2012. Direct ethanol production from hemicellulosic materials of rice straw by use of an engineered yeast strain codisplaying three types of hemicellulolytic enzymes on the surface of xylose-utilizing Saccharomyces cerevisiae cells. J Biotechnol 158 (4): 203-210.

Sluiter A, Hames B, Ruiz R, Scarlata C, Sluiter J, Templeton D, Crocker D. 2012. Determination of Structural Carbohydrates and Lignin in Biomass. Laboratory Analytical Procedure (LAP), National Renewable Energy Laboratory (NREL). Colorado.

Takeshita R, Saigusa N, Teramoto Y. 2016. Production and antioxidant activity of alcoholic beverages made from various cereal grains using Monascus purpureus NBRC 5965. J Inst Brew 122: 350-354.

Vassilev SV, Vassileva CG, Baxter D. 2014. Trace element concentration and associations in some biomass ashes. Fuel 129: 292-313

Volynets B, Dahman Y. 2011. Assessment of pretreatments and enzymatic hydrolysis of wheat straw as a sugar source for bioprocess industry. Intl J Energ Environ 2 (3): 427-446.

Yang Z, Mei J, Liu Z, Huang G, Huang G, Han L. 2018. Visualization and semiquantitative study of the distribution of major components in wheat straw in mesoscopic scale using Fourier transform infrared microspectroscopic imaging. Anal Chem 90 (12): 7332-7340.

Yu X, Liu Y, Cui Y, Cheng Q, Zhang Z, Lu JH, Meng Q, Teng L, Ren X. 2015. Measurement of filter paper activities of cellulose with microplate-based assay. Saudi J Biol Sci 23: S93-S98.

Zhang H, Thygesen LG, Mortensen K, Kádár Z, Lindedam J, Jørgensen H, Felby C. 2014. Structure and enzymatic accessibility of leaf and stem from wheat straw before and after hydrothermal pretreatment. Biotechnol Biofuels 7: 74. DOI: 10.1186/1754-6834-7-74. 